\title{
ABHANDLUNGEN
}

DER AKADEMIE DER WISSENSCHAFTEN DER DDR Abteilung Veröffentlichungen der Wissenschaftlichen Räte Jahrgang $1977 \cdot \mathrm{Nr}$ W 4

\section{Die Aufgaben}

des wissenschaftlich-technischen

Rechtsschutzes bei der Gestaltung der entwickelten sozialistischen Gesellschaft 
Herausgegeben im Auftrage des Präsidenten

der Akademie der Wissenschaften der DDR

von Vizepräsidenten Prof. Dr. Heinrich Scheel

Verantwortlich für dieses Heft:

Prof. Dr. Gerhard Schüßler

Vorsitzender des Rates für staats- und rechtswissenschaftliche Forschung an der Akademie der Wissenschaften der DDR

Redaktionsschluß: 27.6.1977

Erschienen im Akademie-Verlag, 108 Berlin, Leipziger Straße 3-4

(C) Akademie-Verlag Berlin 1977

Lizenznummer: $202 \cdot 100 / 261 / 77$

Gesamtherstellung: VEB Druckhaus Köthen

Bestellnummer: $7534616(2001 / 77 / 4 / \mathrm{W}) \cdot$ I.SV 0485

Printed in GDR

DDR $6,50 \mathrm{M}$ 